\title{
Effects of Catecholamine Depletion on Alertness and Mood in Rested and Sleep Deprived Normal Volunteers
}

Una D. McCann, M.D., David M. Penetar, Ph.D., Yavin Shaham, Ph.D., Droid R. Thorne, Ph.D., Helen C. Sing, B.S., Maria L. Thomas, B.A., I. Christian Gillin, M.D., and Gregory Belenky, M.D.

Npha-methyl-para-tyrosine (AMPT), a tyrosine hydroxylase inhibitor, was used to evaluate the mysiologic role of central nervous system catecholamines modulating alertness and mood. Forty healthy males une randomized to one of four conditions: AMPT in a wed condition; AMPT plus 40.5 hours of total sleep Lquivation; placebo plus sleep deprivation; or placebo in insted condition. Repeated measures of alertness and ood revealed that treatment with AMPT or sleep Iprization increased sleepiness, and combined treatment moduced greater sleepiness than either treatment alone.
In contrast, although combined treatment with AMPT and sleep deprivation led to large increases in negative mood, neither treatment alone produced consistent mood changes. These findings are consistent with the view that sleep deprivation is associated with decreased functional catecholamine neurotransmission. Furthermore, mood effects following sleep deprivation plus AMPT suggest that catecholamines may be involved in mood changes during sleep deprivation. [Neuropsychopharmacology 8:345-356, 1993]
Tr wORDs: Sleep deprivation; Alertness; Mood; Cutcholamines; Monoamines

There is considerable pharmacologic evidence that centol nervous system (CNS) catecholamines are impormont modulators of arousal in man. For example, timulants such as amphetamine effectively reverse decrements in alertness and cognitive performance aswoated with sleep deprivation (Weiss and Laties 1962).

from the Department of Behavioral Biology; Walter Reed Army totute of Research (UDM, DMP, DRT, HCS, MLT, GB), Washing$m . D C$; Section on Anxiety and Affective Disorders, Biological Anchiatry Branch (UDM), National Institute of Mental Health, Vitional Institutes of Health, Bethesda, Maryland; Department of Mrchology, Concordia University (YS), Montreal, Quebec, Canada; Department of Psychiatry, University of California, and Psychiatry Senixe, San Diego V.A. Medical Center (JCG), San Diego, California. Address correspondence to: Una D. McCann, Section on Anxiety Affective Disorders, National Institute of MentalHealth, Building

D. Room 3S-239, 9000 Rockville Pike, Bethesda, Maryland 20892.

Received July 1, 1992; revised October 28, 1992; accepted November X 1992.
The restorative actions of amphetamine are thought to be secondary to functional increases in catecholamine neurotransmission (Glowinski et al. 1966). Conversely, drugs that decrease catecholamine activity also influence arousal. In general, drugs that inhibit noradrenergic or dopaminergic activity increase daytime sleepiness. For example, a variety of catecholamine receptor blockers cause sedation, fatigue, and sleepiness (Betts 1981) and decrease sleep latency times (Nicholson and Pascoe 1990).

Further evidence for catecholaminergic involvement in arousal stems from clinical observations made in a variety of patient populations treated with alphamethyl-para-tyrosine (AMPT); AMPT is a selective catecholamine synthesis inhibitor that can be utilized to determine the involvement of catecholamines in behavior (Nagatsu et al. 1964; Spector et al. 1965). In patient populations, AMPT has been noted to produce sedation early in the course of treatment (Engelman et al. 1968; Jonsson et al. 1971; Ahlenius et al. 1973; 
Pozuelo 1976; Nasrallah et al. 1977). In addition, it has been noted that discontinuation of AMPT treatment is associated with insomnia and decreased total sleep (Bunney et al. 1971, 1977). This observed rebound insomnia has been postulated to be secondary to an increase in catecholaminergic activity. Further evidence for catecholaminergic involvement in the sleep-wake cycle has been reviewed elsewhere (Mendelson 1987).

In addition to their importance in sleep, there is considerable pharmacologic evidence that brain catecholamines are involved in the regulation of mood (Schildkraut 1965; Bunney and Davis 1965; Greenspan et al. 1969; Iqbal et al. 1989; Schildkraut et al. 1973a, 1973b; Goodwin and Post 1975), although the relationship between sleep and mood is complex. For example, major depression is associated with objective electroencephalographic sleep abnormalities (Kupfer and Thase 1983; Gillin 1983), and manic patients typically have decreased sleep, particularly during the period when they switch into mania (Bunney et al. 1972). Further suggesting a link between the regulation of mood and arousal is the observation that the majority of depressed patients exhibit symptomatic improvement following one night of total sleep deprivation (Vogel et al. 1975). The mechanism by which sleep deprivation improves mood in depressed individuals remains unclear, but may involve catecholamines (Siegel and Rogawski 1988; Hartmann and Schildkraut 1973; Schildkraut et al. 1973b; Post et al. 1976; Mogilnicka et al. 1986).

Despite the growing clinical interest in the relationship between sleep and mood, few studies have reported on the effects of one night of sleep deprivation on mood in healthy populations (Gemer et al. 1979; Gillberg and Akerstedt 1981), and of these, results have varied. Moreover, no study that has investigated the effect of sleep deprivation on mood in normal volunteers has used a rested control group. The purpose of this study was twofold: first, to systematically evaluate the effects of sleep deprivation on self-reported mood in healthy volunteers; and second, to use AMPT as a pharmacologic probe for assessing the role of catecholamine neurotransmitters in changes of alertness and mood associated with sleep deprivation. The present study was performed as part of a larger research project investigating the role of catecholamines in alertness, sleep, performance, and mood.

\section{METHODS}

\section{Subjects}

Forty healthy men with a mean age of 25 years (range 21 to 36) were recruited through advertisements in local newspapers. After an initial telephone screen, interested volunteers came to the laboratory for a more detailed evaluation. After informed consent was ob- tained, subjects completed a Beck Depression Inventory ([BDI] Beck et al. 1961) and underwent a thorough physical and laboratory examination, including an elec. trocardiogram, psychiatric screening, SMA-20, thyroid function tests, hepatitis screen, human immunodef. ciency virus testing, complete blood count, urinalysis, and urine drug screen for drugs of abuse. Exclusion criteria included self-reported past or present major medical or psychiatric illness, positive urine drug screens, a score of 10 or greater on the BDI, regular tobacco use, ingestion of more than three cups of coffee (or the equivalent) per day, or atypical sleeping patterns (including unusually delayed or advanced sleep phases, history of insomnia or hypersomnia, or habitual sleep hours not occurring between 2000 and 1000 hours). Following completion of screening procedures, subjects were randomly assigned to one of four treatment con. ditions: 1) treatment with AMPT in a rested state (AMPT/R); 2) treatment with AMPT plus sleep deprivation (AMPT/SD); 3) treatment with placebo plus sleep deprivation $(\mathrm{P} / \mathrm{SD})$; or 4) treatment with placebo in a rested state $(P / R)$. A schematic time line of study proce dures is depicted in Figure 1.

\section{Drug Administration}

Drugs were administered in a double-blind fashion, with subjects from both drug conditions included in each study run, beginning at 1430 hours on treatment day 1 (TD1). Subsequent doses were administered at 1830 and 2330 hours on TD1, and at 0730, 1330, 1830, and 2330 hours on treatment day 2 (TD2). Each of the seven doses contained $750 \mathrm{mg}$ AMPT (or lactose placebo), for a total of $5.25 \mathrm{~g}$ AMPT over a 33-hour period. Previous studies have shown that this regimen depletes cerebrospinal fluid catecholamines by $68 \%$ to $77 \%$ at ter 24 hours (Brodie et al. 1971). Subjects treated with AMPT in the present study had significant elevations in serum prolactin concentrations on day 2 , indicating depletion of CNS catecholamines at the level of the

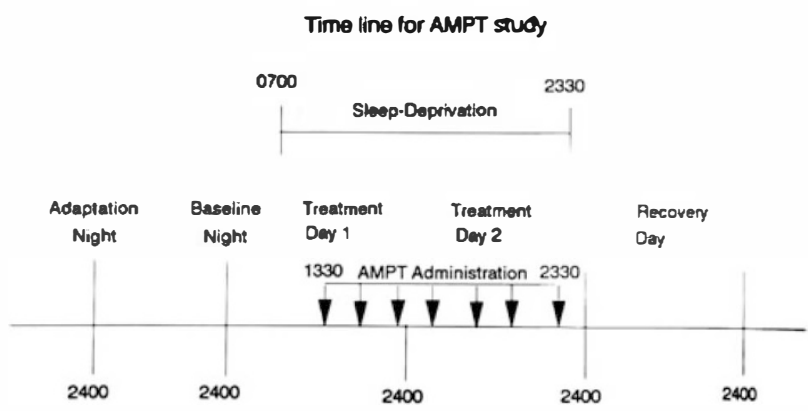

Figure 1. Generalized time line for study procedures. Following adaptation and baseline sleep nights, subjects were sleep deprived for $\mathbf{4 0 . 5}$ hours (treatment days 1 and 2). During the sleep-deprivation period, subjects received seven doses of AMPT (750 mg/dose) or placebo. 
Thpothalamus (McCann et al. 1992). Subjects received in last dose of AMPT immediately before recovery unp, at the end of the sleep-deprivation period.

\section{mep Deprivation}

hiviously described methods for sleep-deprivation and poformance assessment were used, with minor modmation (Newhouse et al. 1989). Briefly, following an duptation sleep night in the laboratory and training a computerized performance assessment battery (Nalter Reed Army Institute of Research Performance Aressment Battery, WRAIR PAB [Thorne et al. 1985]), tijects were monitored polysomnographically for meline sleep using an Oxford Medilog Recorder. Adptation and baseline sleep hours were between 2330 and 0700. The next morning (TD1), subjects were inmoned as to whether they had been randomized to the cep-deprived (no sleep for 43 hours) or rested (7 1/2 burs of sleep nightly) condition. Rested and sleepeprived study runs were conducted separately, both eccuse of the logistics involved in running both sleep anditions simultaneously, and because of possible conbunding or adverse psychologic effects secondary to mnning both sleep conditions simultaneously (e.g., it spossible that a subject who was required to remain wake while others were allowed to sleep would be morelikely to report negative mood states). Sleep depriration took place from 0700 hours on TD1 until 2330 burs on TD2. All subjects slept from 2330 on TD2 un$\$ 0700$ on recovery day (recovery sleep). During sleep deprivation and during the day after recovery sleep, xbjects took repeated measures of performance and mod. Additionally, subjects took modified Multiple Seep Latency Tests (MSLTs; Carskadon and Dement 192) as an objective measure of sleepiness. During each modified MSLT, subjects were awakened as soon as they fell asleep (within 30 seconds), to maximize the effects of sleep deprivation. This study routine continued for sleep-deprived subjects at a slower pace during the time that rested subjects slept, to keep subjects x similar activity levels as during the day, and at the seme time minimize the possibility that testing procedures themselves would confound the data. During the two treatment days and recovery day, sleep-deprived subjects completed 25 WRAIR PABs (rested subjects completed 21), 17 modified SLTs (rested subjects completed 15), and 13 visual analogue scales (VAS) (rested subjects completed 12). Rested subjects were not wakened to collect data, and the data collected from deepdeprived subjects during the time that rested subincts slept was not used in statistical comparisons. Data trom the cognitive tasks, sleep latency tests, and the Stanford Sleepiness Scale (SSS) (Hoddes et al. 1973) has been reported elsewhere (McCann et al. 1992).

\section{Alertness and Mood Measures}

Simultaneous measures of alertness and mood were taken during the two sleep-deprivation and drugtreatment days (TD1 and TD2) and the day following recovery sleep(recovery day). Measurements included a pencil and paper VAS designed to measure global vigor and affect (Monk 1989), and a computerized version of the Profile of Mood States ([POMS] McNair et al. 1971) which is incorporated into the WRAIR PAB. These measures were chosen because they have been validated in studies assessing mood changes in depressed patients and normal controls (Gillin et al. 1989; Wehr et al. 1985), and because unlike the MSLT and SSS, these measures assess both alertness and mood scales using identical testing methods.

Visual Analogue Scale. All subjects completed three VAS questionnaires on TD1, four VAS questionnaires during TD2, and four VAS questionnaires during recovery day. Subjects were presented with eight questions, each pertaining to a particular mood. Below each question was a $100-\mathrm{mm}$ line on which they placed a mark indicating their self-rating on the mood in question at the time the questionnaire was administered. Labels at the two ends of the line indicated the opposite extremes of the mood. Mood scales on the VAS included alertness, sleepiness, weariness, effort required to complete tasks, happiness, sadness, tension, and calmness. Possible scores ranged from 0 to 100 .

Profile of Mood States. All subjects took five POMS questionnaires during TD1, seven POMS questionnaires on TD2, and eight POMS questionnaires on recovery day. The POMS requires a subject to rate a level of agreement or disagreement to a list of 65 adjectives or phrases. Mood scales on the POMS include Vigor-Activity(Vigor), Fatigue-Inertia (Fatigue), Depression-Dejection (Depression), Anger-Hostility (Anger), Tension-Anxiety (Tension), and ConfusionBewilderment (Confusion).

\section{Data Analysis}

A 2 (sleep condition: sleep-deprived/rested) $\times 2$ (drug: AMPT/placebo) repeated-measures analysis of covariance (ANCOVA) was used to evaluate the effects of AMPT administration and sleep deprivation on the alertness and mood scales of the POMS and VAS tests. Test scores in the morning ( 0800 to 1200 hours) of TD1, prior to drug administration, were used as covariates for the analyses of the above mentioned variables. Repeated-measures analyses were conducted separately for the treatment phase of the experiment (TD1 and TD2), and for recovery day. In cases where there was a significant main effect of sleep condition or drug treatment, a sleep condition $\times$ drug treatment interac- 
tion or time $\times$ main effect(s) interaction(s), simple ANCOVAs were conducted within each individual time point. When simple main effects were observed within a particular time point, post hoc analyses (Duncan tests) were performed to determine which of the four treatment groups differed significantly. However, since there are six possible post hoc comparisons at each time point, only results of the post hoc analyses pertinent to experimental hypotheses are mentioned. Furthermore, due to a large number of statistical comparisons, results were considered significant at a level of $p<.01$, and only significant and near significant results pertinent to the discussion are reported. Finally, although more measurements of the POMS were taken during the experiment, the data analyses include only datapoints when both the POMS and the VAS were administered (Of note, analysis including all time points yielded the same results as those reported here). All statistical analyses were performed using Statistical Analysis Systems (SAS, Cary, NC).

\section{RESULTS}

Results from the overall repeated-measures ANCOVA during treatment days 1 to 2 and during recovery day are presented in Tables 1 and 2 respectively. Results from the simple ANCOVA and post hoc Duncan tests are reported below.

\section{Measures of Alertness and Fatigue}

Measures of Alertness. As shown in Fig. 2, scores of "alertness" from the VAS and "vigor" from the POMS indicate that: 1) during TD2, decreased alertness was observed due to both sleep deprivation and AMPT administration; 2) the effect of AMPT on alertness is more pronounced than the effect of sleep deprivation (e.g., the AMPT/R group differed significantly from the P/SD group between 1200 of TD2 and 1200 of the recovery day in the VAS alertness scale); 3) AMPT plus sleep deprivation led to greater decreases in alertness than

Table 1. Summary of AMPT Effects, Sleep Deprivation Effects, and AMPT by Sleep Deprivation Interaction Effects Across Time During Treatment Days 1 and 2

\begin{tabular}{|c|c|c|c|c|c|}
\hline $\begin{array}{c}\text { Type of } \\
\text { Effect }\end{array}$ & $\begin{array}{c}\text { AMPT } \\
\text { Effect } \\
d f=1,35\end{array}$ & $\begin{array}{l}\text { SD Effect } \\
d f=1,35\end{array}$ & $\begin{array}{c}\text { AMPT by } \\
\text { Time } \\
\text { Effect } \\
d f=5,175\end{array}$ & $\begin{array}{c}\text { SD by Time } \\
\text { Effect } \\
d f=5,175\end{array}$ & $\begin{array}{c}\text { Time } \\
\text { Effect } \\
d f=5,175\end{array}$ \\
\hline $\begin{array}{l}\text { Alertness } \\
\text { scale VAS }\end{array}$ & $F=36.1^{\star \star}$ & NS & $F=13.5^{\star \star}$ & $F=3.9^{\star \star}$ & NS \\
\hline $\begin{array}{l}\text { Vigor } \\
\text { scale POMS } \\
\text { Sleepiness }\end{array}$ & $F=22.2^{\star *}$ & $F=11.1^{\star *}$ & $F=6.9^{\star *}$ & NS & NS \\
\hline & $F=23.1^{\star \star}$ & $F=7.4^{\star \star}$ & $F=11.5^{\star *}$ & $F=8.2^{\star \star}$ & $F=13.9^{\star \star}$ \\
\hline & $F=21.6^{* *}$ & $F=16.5^{\star \star}$ & $F=8.1^{\star \star}$ & $F=8.3^{\star \star}$ & $F=10.1^{\star \star}$ \\
\hline $\begin{array}{l}\text { scale VAS } \\
\text { Fatigue }\end{array}$ & $F=5.6^{\star}$ & NS & $F=9.6^{\star \star}$ & $F=6.9^{\star \star}$ & $F=16.1^{\star \star}$ \\
\hline $\begin{array}{l}\text { scale POMS } \\
\text { Sadness }\end{array}$ & $F=12.8^{\star \star}$ & $F=14.6^{\star \star}$ & $F=6.6^{\star \star}$ & $F=5.8^{\star \star}$ & $F=5.3^{\star \star}$ \\
\hline $\begin{array}{l}\text { scale VAS } \\
\text { Tension }\end{array}$ & NS & NS & $F=2.4^{\star}$ & $F=5.2^{\star \star}$ & $F=5.2^{\star \star}$ \\
\hline $\begin{array}{l}\text { scale VAS } \\
\text { Depression }\end{array}$ & NS & $F=5.1^{*}$ & $F=2.3^{\star}$ & $F=3.1^{\star \star}$ & $F=9.1^{\star \star}$ \\
\hline $\begin{array}{l}\text { scale POMS } \\
\text { Tension }\end{array}$ & $F=8.7^{\star *}$ & $9.8^{\star \star}$ & $7.0^{\star \star}$ & $5.8^{\star \star}$ & NS \\
\hline $\begin{array}{l}\text { scale POMS } \\
\text { Anger }\end{array}$ & $F=5.8^{\star}$ & $F=7.8^{\star \star}$ & $F=4.7^{\star \star}$ & $F=4.9^{\star \star}$ & $F=4.8^{\star \star}$ \\
\hline $\begin{array}{l}\text { scale POMS } \\
\text { Happiness }\end{array}$ & $F=8.5^{\star \star}$ & $F=7.5^{\star \star}$ & $F=2.9^{\star}$ & NS & NS \\
\hline $\begin{array}{l}\text { scale VAS } \\
\text { Calmness }\end{array}$ & $F=13.2^{\star \star}$ & $F=5.1^{\star}$ & $F=2.7^{\star}$ & NS & $F=9.3^{\star \star}$ \\
\hline scale VAS & NS & $F=7.0^{\star}$ & $F=2.4^{\star}$ & $F=2.7^{\star}$ & NS \\
\hline
\end{tabular}

* Approaching significant effects, $p<.05$.

** Significant effects, $p<.01$.

Abbreviation: SD, sleep deprivation.

Note: No significant AMPT by SD or AMPT by SD by time effect was observed. 
Table 2. Summary of AMPT Effects, Sleep Deprivation Effects, and AMPT by Sleep Deprivation Interaction Effects Across Time During Recovery Days

\begin{tabular}{|c|c|c|c|c|c|}
\hline $\begin{array}{c}\text { Type of } \\
\text { Effect }\end{array}$ & $\begin{array}{c}\text { AMPT } \\
\text { Effect } \\
d f=1,35\end{array}$ & $\begin{array}{l}\text { SD Effect } \\
d f=1,35\end{array}$ & $\begin{array}{c}\text { AMPT by } \\
\text { Time } \\
\text { Effect } \\
d f=3,105\end{array}$ & $\begin{array}{c}\text { SD by Time } \\
\text { Effect } \\
d f=3,105\end{array}$ & $\begin{array}{c}\text { Time } \\
\text { Effect } \\
d f=3,105 \\
\end{array}$ \\
\hline $\begin{array}{l}\text { Alertness } \\
\text { scale VAS } \\
\text { Vigor }\end{array}$ & $F=8.0^{\star \star}$ & NS & $F=2.8^{\star \star}$ & NS & NS \\
\hline $\begin{array}{l}\text { Vigor } \\
\text { scale POMS } \\
\text { Sleepiness }\end{array}$ & $F=11.6^{\star \star}$ & NS & NS & NS & NS \\
\hline $\begin{array}{l}\text { scale VAS } \\
\text { Weariness }\end{array}$ & NS & NS & $F=5.2$ & NS & NS \\
\hline $\begin{array}{l}\text { scale VAS } \\
\text { Effort }\end{array}$ & NS & NS & $F=5.3^{\star \star}$ & NS & NS \\
\hline $\begin{array}{l}\text { scale VAS } \\
\text { Fatigue }\end{array}$ & $F=11.3^{\star \star}$ & NS & NS & NS & NS \\
\hline $\begin{array}{l}\text { scale POMS } \\
\text { Sadness }\end{array}$ & $F=8.2^{\star \star}$ & NS & NS & NS & NS \\
\hline $\begin{array}{l}\text { scale VAS } \\
\text { Tension }\end{array}$ & NS & NS & NS & NS & NS \\
\hline $\begin{array}{l}\text { scale VAS } \\
\text { Depression }\end{array}$ & NS & NS & NS & NS & NS \\
\hline $\begin{array}{l}\text { scale POMS } \\
\text { Tension }\end{array}$ & $F=5.9^{\star}$ & NS & NS & NS & NS \\
\hline $\begin{array}{l}\text { scale POMS } \\
\text { Anger }\end{array}$ & NS & NS & $F=3.7^{\star}$ & NS & $F=4.9^{\star \star}$ \\
\hline $\begin{array}{l}\text { scale POMS } \\
\text { Happiness }\end{array}$ & NS & NS & NS & NS & NS \\
\hline $\begin{array}{l}\text { scale VAS } \\
\text { Calmness }\end{array}$ & $F=4.1^{\star}$ & NS & $F=2.7^{\star}$ & NS & NS \\
\hline scale VAS & NS & NS & NS & NS & NS \\
\hline
\end{tabular}

* Approaching significant effects, $p<.05$.

** Significant effects, $p<.01$.

Abbreviation: SD, sleep deprivation.

Note: No significant AMPT by SD or AMPT by SD by time effect was observed.

ither treatment alone; 4) the AMPT effect persisted during the recovery day; and 5) the effects of AMPT m alertness are not observed until TD2.

Measures of Sleepiness and Fatigue. As shown in Fig. 3, scores of "sleepiness," "weariness," and "effort" from the VAS as well as scores of "fatigue" from the POMS (not shown in Fig. 3) indicate the following: 1) an inarease in fatigue was observed following both sleep deprivation and AMPT administration; 2) during TD2, subjects in the AMPT/SD group had the highest scores on all of the sleepiness scales used; 3 ) on some scales (i.e., effort and sleepiness scales of the VAS) the effect of AMPT per se was more pronounced than the effect of sleep deprivation per se (i.e., significant differences were observed between the AMPT/R and P/SD groups during TD2 and recovery day on many of the data points);4) the effects of AMPT on fatigue persisted after the termination of drug administration; and 5) no difference among the groups was observed during TD1.

\section{Mood Measurements}

Measures of Negative Mood. As shown in Fig. 4 and 5 , scores of "sadness" and "tension" from the VAS, and scores of "tension," "depression," and "anger" from the POMS indicate that: 1) significant main effects of AMPT administration and sleep deprivation on negative mood scales observed in TD2 and recovery day are largely a reflection of high scores reported by the AMPT/SD group at most time points; 2 ) in both the AMPT/R group and the P/SD group, there was a trend for increases in negative mood that did not reach statistical significance, suggesting that for the short duration of this study, neither treatment alone was sufficient to alter negative mood states in the subjects; and 3) drug effects on negative mood states may persist after the termination of the drug administration.

Measures of Positive Mood. As shown in Fig. 6, scores on the "happiness" and "calmness" scales of the VAS 
Figure 2. Self-rated alertness using a VAS (Monk 1989) and vigor using the POMS (McNair et al. 1971). The numbers 1 and 2 denote significant simple main effects $(p<.01)$ of drug and sleep condition, respectively, within an individual time point. The numbers $1^{*}$ and $2^{\star}$ denote relevant near signifıcant simple main effects $(p<.05)$ of drug and sleep condition, respectively, with an individual time point.
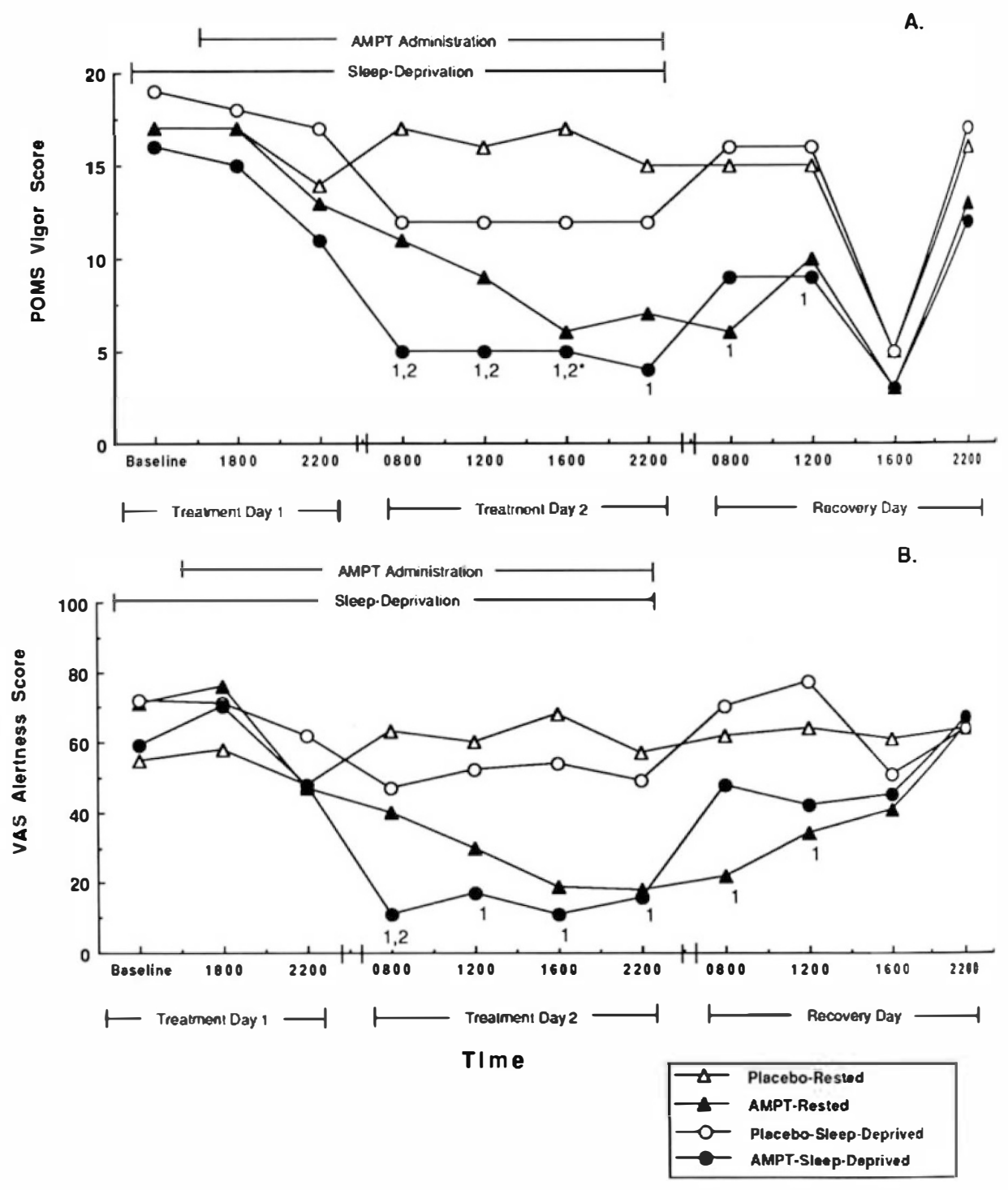

indicate the following: 1) significant main effects of AMPT administration and sleep deprivation on positive mood measures observed during TD2 mainly stem from the fact that the AMPT/SD group had lower scores than the other groups at most time points; 2 ) the lower, although not significant, scores in the happiness scale of the VAS in the AMPT/R and P/SD versus the P/R during TD2, and the approaching significant AMPT effects during the recovery day on this scale may indicate that AMPT administration and sleep deprivation per se decrease positive mood; and 3) AMPT effects on positive mood may persist after the termination of the drug administration.

\section{DISCUSSION}

The findings of this study indicate that, in healthy individuals, a decline in CNS catecholamine concentra- tions leads to increased subjective sleepiness, and are consistent with the view that prolonged wakefulness is associated with a functional decrease in catecholaminergic neurotransmission. The current results confurm previous informal observations in patient populations, where AMPT was observed to produce sedation (Engelman et al. 1968; Jonsson et al. 1971; Ahlenius et al. 1973; Pozuelo 1976; Nasrallah et al. 1977), and extend the observation to healthy populations. The present results are also in concordance with data collected using the modified MSLT and the SSS (McCann et al. 1992). The finding that combined treatment with AMPI and sleep deprivation produced greater changes in subjective measures of sleepiness than either treatment alone supports the notion that both treatments interact with CNS catecholamines.

The present results further indicates that AMPT. induced catecholamine depletion leads to negative 

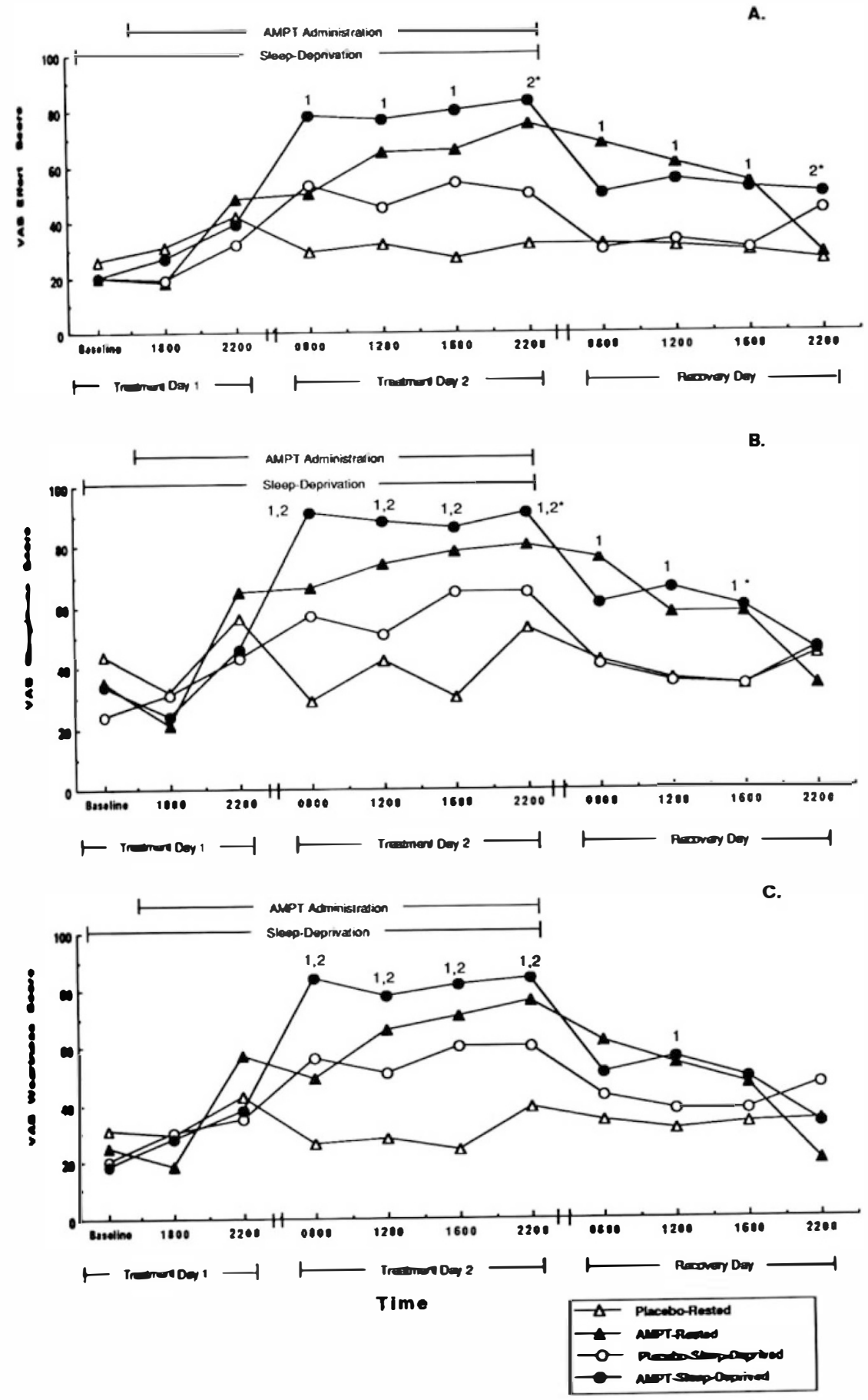

Figure 3. Self-rated sleepiness, weariness, and effort required to complete a task using a VAS (Monk 1989). The numbers 1 and 2 denote significant simple main effects $(p<.01)$ of drug and sleep condition, respectively, within an individual time point. The numbers $1^{\star}$ and $2^{\star}$ denote relevant near significant simple main effects $(p<.05)$ of drug and sleep condition, respectively, with an individual time point. mood in healthy sleep-deprived individuals. In particurr, normal subjects treated with AMPT and subjected \$ 40.5 hours of total sleep deprivation report increased depression, anger, confusion, tension, and anxiety, as well as decreased calmness and happiness. Interestingly, treatment with AMPT or sleep deprivation alone ad to only mild and inconsistent changes in mood. It was only when the two treatments were combined that inificant mood effects were observed, further suggest- ing that the two treatments interact with a common neural substrate (i.e., CNS catecholamines).

Although the effects of AMPT on mood in healthy individuals have not been previously reported, there have been observations on AMPT's effects in patient populations. In a study of 52 patients with a variety of medical conditions, it was noted that some patients developed an "anxiety state" (Engleman et al. 1968b). When given to unmedicated patients with bipolar affec- 
Figure 4. Self-rated sadness and tension over time using a VAS (Monk 1989). The numbers 1 and 2 denote significant simple main effects $(p<.01)$ of drug and sleep condition, respectively, within an individual time point. The numbers $1^{*}$ and $2^{*}$ denote relevant near significant simple main effects $(p<.05)$ of drug and sleep condition, respectively.
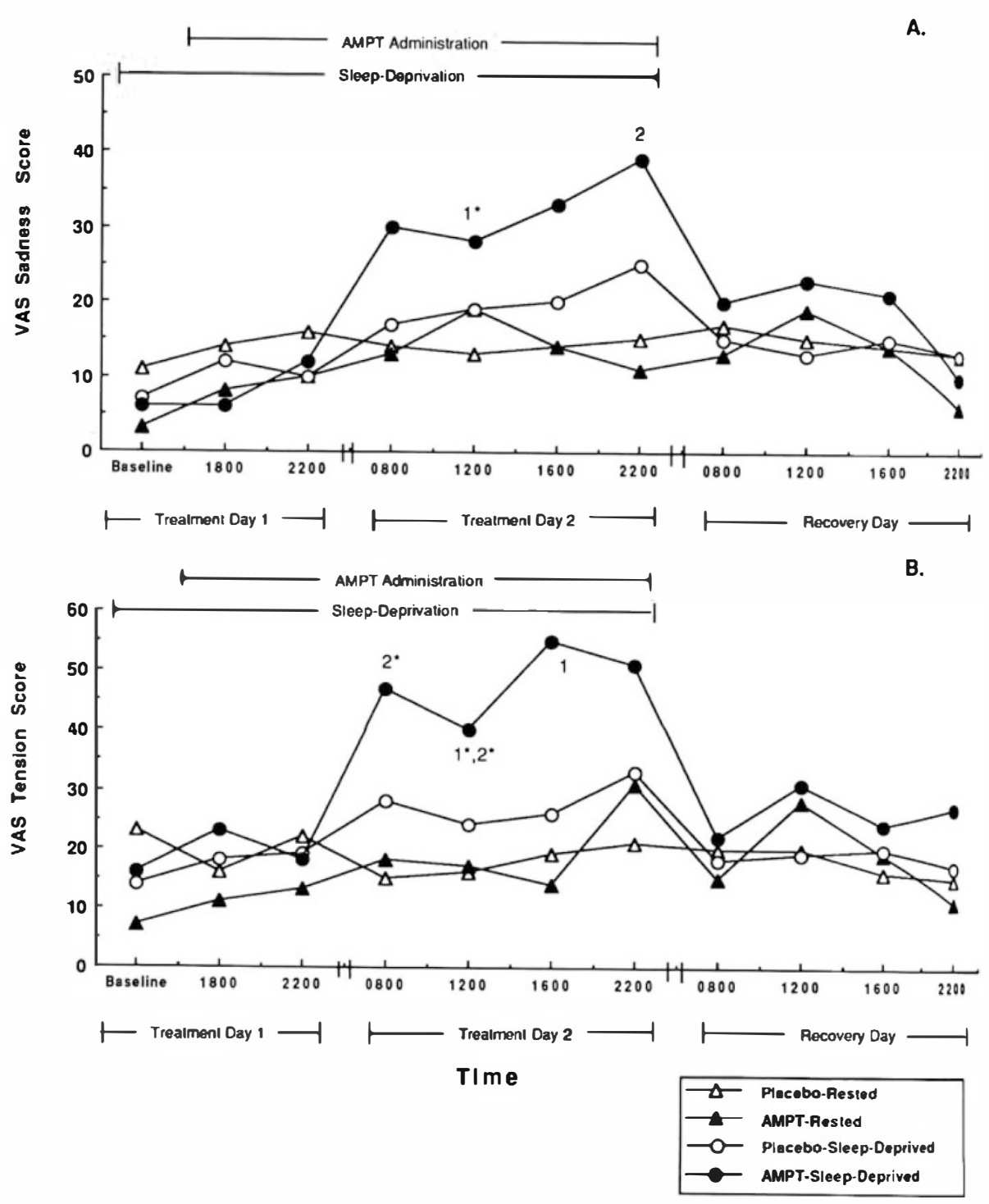

tive disorder, AMPT decreased manic symptoms in five of seven patients, and increased depression in three of three depressed patients (Bunney et al. 1971). These reports, taken with the findings of the present study, lend support to the view that increases in functional catecholamine activity are associated with improved mood, and decreases in catecholamine activity with negative mood states.

Three aspects of the present findings deserve comment. First, it could be that the effects of AMPT are due to nonspecific side effects of the drug. Arguing against this possibility is the finding that the time course of AMPT-related decrements in alertness and mood parallel the time course of catecholamine depletion (Engelman et al. 1968; Rech et al. 1966). In addition, the return of mood and alertness measures to baseline levels paralleled the time course of brain catecholamine recovery, as demonstrated in preclinical animal models, where norepinephrine levels reach control values 24 hours after the last AMPT dose, and dopamine levels reach control values 48 hours after the last AMPT dose (Rech et al. 1966). Second, it is possible that the combination of AMPT and sleep deprivation produced a general dysphoria, leading to a negative response bias where all negative mood states were given high scores. Nevertheless, the fact that only the combination treatment leads to dysphoria and the finding that dysphoric mood parallels the time course of catecholamine depletion, implicates catecholamines in the dysphoria produced during sleep deprivation. Third, although the actions of AMPT are specific to tyrosine hydroxylase (Nagatsu et al. 1964; Spector et al. 1965), and thus do not directly influence metabolism of other neurotrans. mitters, AMPT's actions on catecholaminergic systems could indirectly influence other neurotransmitters or neuropeptides (e.g., serotonin, acetylcholine, cholecys- 

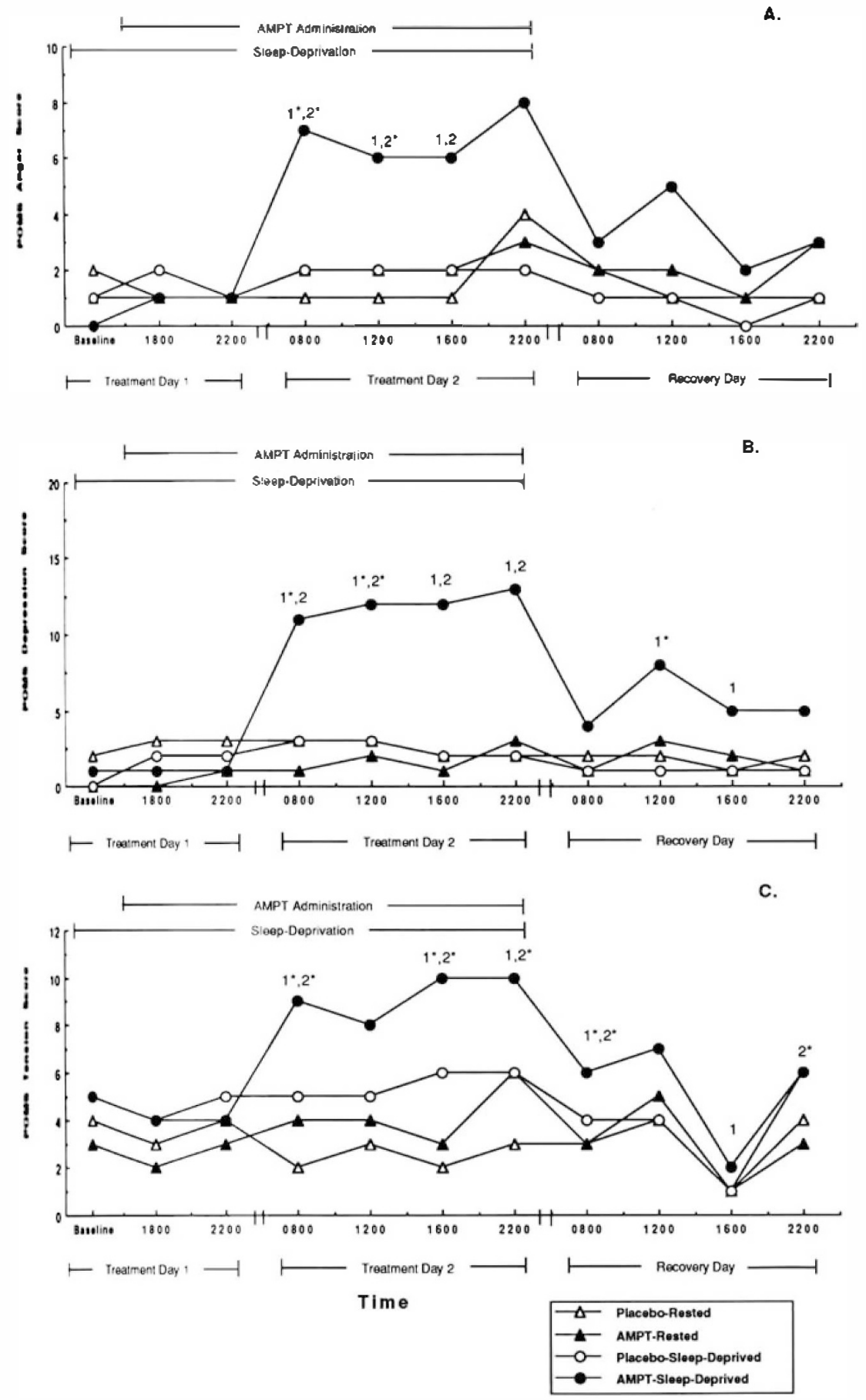

Figure 5. Self-rated tension, depression, and anger over time using the POMS (McNair et al. 1971). The numbers 1 and 2 denote significant simple main effects $(p<.01)$ of drug and sleep condition, respectively, within an individual time point. The numbers $1^{\star}$ and $2^{*}$ denote relevant near significant simple main effects $(p<$ $.05)$ of drug and sleep condition, respectively, with an individual time point. tinin, neuropeptide $Y$ ). As such, secondary changes bother neurotransmitters and neuromodulators may thobe involved in the AMPT-induced changes in mood. Although the relationship between mood and alertmesiscomplex, evaluation of the effects of sleep deprivion and AMPT in depressed patients could shed light inthe extent of catecholamine involvement in the therqutic effects of sleep deprivation. Specifically, AMPT ould be used to test the hypothesis that the antidepres- sant effect of sleep deprivation in depressed patients is related to changes in catecholamine neurotransmission (Siegel and Rogawski 1988). For example, it has been postulated that downregulation of catecholamine neurotransmission caused by sleep deprivation (Stern and Morgane 1974; Mogilnicka et al. 1986; Radulovacki and Micovic 1983) leads to increased catecholamine turnover (Siegel and Rogawski 1988; Reisine 1981; Schildkraut and Hartmann 1972), which in depressed 
Figure 6. Self-rated calmness and happiness using a VAS (Monk 1989). The numbers 1 and 2 denote significant simple main effects $(p<.01)$ of drug and sleep condition, respectively, within an individual time point. The numbers $1^{\star}$ and $2^{\star}$ denote relevant near significant simple main effects $(p<.05)$ of drug and sleep condition, respectively, with an individual time point.
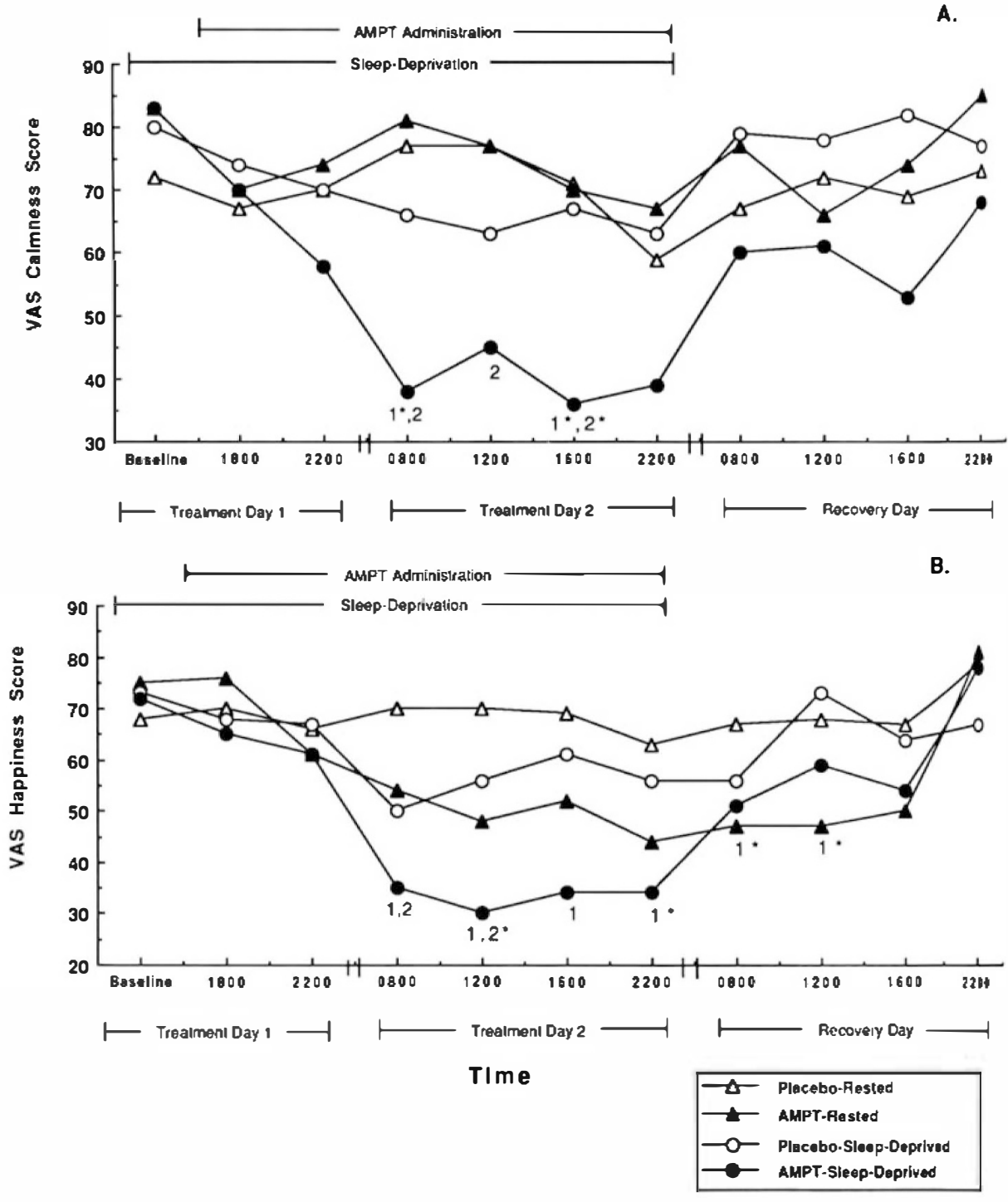

individuals, leads to improved mood. If the antidepressant effect of sleep deprivation requires increased catecholamine turnover (or indeed, requires normal levels of CNS catecholamines), it would be predicted that AMPT treatment would block mood improvements secondary to sleep deprivation.

In summary, the present findings indicate that in healthy adults, treatment with sleep deprivation or AMPT produces sleepiness, and that combined treatment with sleep deprivation and AMPT produces greater sleepiness than either treatment alone. In contrast, only combined treatment with AMPT plus sleep deprivation leads to marked increases in anxiety, depression, and anger, with either treatment alone producing only moderate and inconsistent mood changes. The observation that sleep deprivation and catecholamine depletion interact to influence alertness and mood is consistent with the view that catechol- amines play a role in alertness, and suggests that catecholamine systems are involved in mood changes as sociated with sleep deprivation.

\section{ACKNOWLEDGMENT}

The authors gratefully acknowledge the Student Employees of the Continuous Operations Branch for their technical as sistance, and without whom this research could nothave been conducted.

\section{DEPARTMENT OF DEFENSE DISCLAIMER}

Human volunteers participated in this study after giving theis free and informed consent. Investigators adhered to AR 7 25 and USAMRDC Reg 70-50 on the use of volunteers in re search. The opinions or assertations contained herein are the 
private views of the authors and are not to be construed as oficil or as reflecting the views of the Department of the Amy or the Department of Defense.

\section{REFERENCES}

Ahenius S, Carlsson A, Engel J, Svensson T, Sodersten FK (1973): Antagonism by alpha methyltyrosine of ethanolinduced stimulation and euphoria in man. Clin Pharmacol Ther 14:586-591

leck AT, Ward CM, Mendelson M, Moch T, Erbaugh J (1961): An inventory for measuring depression. Arch Gen Psychiatry 4:561-571

Wtts TA (1981): Adrenoceptor drugs and sleep. In Wheatley D (ed), Psychopharmacology of Sleep. New York, Raven Press, pp 199-212

hodie HKH, Murphy DL, Goodwin FK, Bunney WE (1971): Catecholamines and mania: The effect of alpha-methylpara-tyrosine on manic behavior and catecholamine metabolism. Clin Pharmacol Exp Ther 12:218-224

unney WE Jr, Davis JM (1965): Norepinephrine in depressive reactions. Arch Gen Psychiatry 13:483-494

bunney WE, Brodie HK, Murphy DL, Goodwin FK (1971): Studies of alpha-methyl-para-tyrosine, L-dopa, and L-tryptophan in depression and mania. Am J Psychiatry 127:872-881

Cunney WE Jr, Goodwin FK, Murphy DL, House KM, Gordon EK (1972): The "switch process" in manic-depressive illness. II. Relationship to catecholamines, REM sleep, and drugs. Arch Gen Psychiatry 27:304-309

cunney WE, Kopanda RT, Murphy DL (1977): Sleep and behavioral changes possibly reflecting central receptor hypersensitivity following catecholamine synthesis inhibition in man. Acta Psychiatr Scand 56:189-203

Grskadon MA, Dement WC (1982): The multiple sleep latency test: What does it measure? Sleep 5:S67-72

Ergelman K, Horwitz D, Jequier E, Sjoerdsma A (1968): Biochemical and pharmacologic effects of alpha-methyltyrosine in man. J Clin Invest 47:577-594

Cemer RH, Post RM, Gillin JC, Bunney WE (1979): Biological and behavioral effects of one nights sleep deprivation in depressed patients and normals. J Psychiatry Res 15:21-40

Cilberg M, Akerstedt T(1981): Sleep deprivation in normalssome psychological and biochemical data from three studies. In Koella WP (ed), Sleep 1980: Proceedings of the 5thEuropean Congress on Sleep Research. Amsterdam, Karger, pp 16-22

Cin JC (1983): Sleep studies in affective illness: Diagnostic, therapeutic, and pathophysiological implications. Psychiatry Ann 13:367-382

Clin JC, Kripke DF, Janowsky DS, Risch SC (1989): Effects of brief naps on mood and sleep in sleep-deprived depressed patients. Psychiatry Res 27:253-265

Cowinski J, Axelrod J, Iversen LL (1966): Regional studies of catecholamines in the rat brain. IV. Effects of drugs on the disposition and metabolism of ${ }^{3} \mathrm{H}$-norepinephrine and ${ }^{3} \mathrm{H}$-dopamine. J Pharmacol Exp Ther 153:30-41

Coodwin FK, Post RM (1975): Studies of amine metabolites in affective illness and in schizophrenics: A comparative analysis. In Freedman DX(ed), The Biology of the Major Psychoses. New York, Raven Press, pp 247-258

Greenspan K, Schildkraut JJ, Gordon EK, Levy B, Durell J (1969): Catecholamine metabolism in affective disorders. II. Norepinephrine, normetanephrine, epinephrine, metanephrine, and VMA excretion in hypomanic patients. Arch Gen Psychiatry 21:710-716

Hartmann E, Schildkraut JJ (1973): Desynchronized sleep and MHPG excretion: An inverse correlation. Brain Res 61: 412-416

Hoddes E, Zarcone V, SmytheH, Phillips R, Dement W (1973): Quantification of sleepiness: A new approach. Psychophysiology 10:431-436

Iqbal N, Bajwa W, Asnis G (1989): The role of norepinephrine in depression. Psychiatry Ann 19:354-359

Jonsson LE, Anggard E, Gunne LM (1971): Blockade of intravenous amphetamine euphoria in man. Clin Pharmacol Ther 12:889-896

Kupfer DJ, Thase ME (1983): The use of the sleep laboratory in the diagnosis of affective disorders. Psychiatr Clin North Am 6:3-25

McCann UD, Penetar DM, Shaham Y, Thorne D, Gillin JC, Sing HC, Thomas ML, Belenky G (1992): Sleep deprivation and impaired cognition: Possible role of brain catecholamines. Biol Psychiatry 31:1082-1097

McNair DM, Lorr M, Droppleman LF (1971): Profile of Mood States. San Diego, Educational and Industrial Testing Service

Mendelson WB (1987): Pharmacology and neurotransmitters in sleep. In Mendelson WB (ed), Human Sleep. New York, Plenum Medical Book Co, pp 33-78

Mogilnicka E, Przewlocka B, van Luijtelaar ELJM, Klimek V, Coenen AML (1986): Effects of REM sleep deprivation on central alpha 1- and beta-adrenoceptors in rat brain. Pharmacol Biochem Behav 25:329-332

Monk TH (1989): A visual analogue scale technique to measure global vigor and affect. Psychiatry Res 27:89-99

Nagatsu T, Levitt M, Udenfriend S (1964): Tyrosine hydroxylase, the initial step in norepinephrine biosynthesis. J Biol Chem 239:2910-2917

Nasrallah HA, Donnelly EF, Bigelow LB, Rivera-Calimlim L, Rogol S, Rauscher FP, Wyatt RJ, Gillin JC (1977): Inhibition of dopamine synthesis in chronic schizophrenia. Arch Gen Psychiatry 34:649-655

Newhouse PA, Belenky G, Thomas ML, Thorne D, Sing HC, Fertig J (1989): The effects of $d$-amphetamine on arousal, cognition, and mood after prolonged total sleep deprivation. Neuropsychopharmacology 2:153-164

Nicholson AN, Pascoe PA (1990): Dopaminergic transmission and the sleep-wakefulness continuum in man. Neuropharmacology 4:411-417

Post R, Kotin J, Goodwin FK (1976): Effects of sleep deprivation on mood and central amine metabolism in depressed patients. Arch Gen Psychiatry 33:627-632

Pozuelo J (1976): Suppression of craving and withdrawal in humans addicted to narcotics or amphetamines by administration of alpha-methyl-para-tyrosine (AMPT) and 5-butylpicolinic acid (fusaric acid). Cleve Clin Q 43:89-94 
Radulovacki M, Micovic N (1982): Effects of REM sleep deprivation and desipramine on beta-adrenergic binding sites in rat brain. Brain Res 235:393-396

Rech RH, Borys HK, Moore KE (1966): Alterations in behavior and brain catecholamine levels in rats treated with alphamethyl-para-tyrosine. J Pharmacol Exp Ther 153:412-419

Reisine T (1981): Adaptive changes in catecholamine receptors in the central nervous system. Neuroscience 6:14711502

Schildkraut JJ (1965): The catecholamine hypothesis of affective disorders: A review of supporting evidence. Am J Psychiatry 122:509-522

Schildkraut JJ, Hartmann E (1972): Turnover and metabolism of norepinephrine in rat brain after 72 hours on a D-deprivation island. Psychopharmacology 27:17-27

Schildkraut JJ, Keeler BA, Grab EL, Kantrowich J, Hartmann E (1973a): MHPG excretion and clinical classification in depressive disorders. Lancet 1:1251-1252

Schildkraut JJ, Keeler BA, Papousek M, Hartmann E (1973b): MHPG excretion in depressive disorders: Relation to clinical subtypes and desynchronized sleep. Science 181: 762-764
Siegel JM, Rogawski MA (1988): A function for REM sleep. Regulation of noradrenergic receptor sensitivity. Brain Res Rev 13:213-233

Spector S, Sjoerdsma A, Udenfriend S (1965): Blockaded endogenous norepinephrine synthesis by alpha-methypara-tyrosine, an inhibitor of tyrosine hydroxylase. Pharmacol Exp Ther 147:86-95

Stern WC, Morgane PJ (1974): Theoretical view of REM sleep function: Maintenance of catecholamine systems in th central nervous system. Behav Biol 11:1-32

Thorne D, Genser S, Sing H, Hegge F (1985): The Walter Red performance assessment battery. Neurobehav Toxid Teratol 7:415-418

Vogel GW, Thurmond S, Gibbons R, Sloan K, Walker N (1975): REM sleep reduction effects on depression sy? dromes. Arch Gen Psychiatry 32:765-777

Wehr TA, Rosenthal NE, Sack DA, Gillin JC (1985): Ar tidepressant effects of sleep deprivation in bright and din light. Acta Psychiatr Scand 72:161-165

Weiss B, Laties VG (1962): Enhancement of human perfor. mance by caffeine and the amphetamines. Pharmacol Ro $14: 1-36$ 